\title{
Extratropical cyclone climatology across eastern Canada
}

\author{
Mathieu Plante, ${ }^{\text {a }}$ Seok-Woo Son, ${ }^{\text {b* }}$ Eyad Atallah, ${ }^{\text {a }}$ John Gyakum ${ }^{\mathrm{a}}$ and Kevin Grise ${ }^{\mathrm{c}}$ \\ a Department of Atmospheric and Oceanic Sciences, McGill University, Montreal, Canada \\ ${ }^{\mathrm{b}}$ School of Earth and Environmental Sciences, Seoul National University, South Korea \\ ${ }^{\mathrm{c}}$ Lamont-Doherty Earth Observatory, Columbia University, Palisades, NY, USA
}

\begin{abstract}
Extratropical cyclone (ETC) tracks across eastern Canada are examined by applying a Lagrangian tracking algorithm to the lower-tropospheric relative vorticity field of reanalysis data. Both the seasonal cycle and the interannual variability of ETCs are quantified in terms of overall cyclone frequency, intensity, and regions of development and decay. We find that ETCs travelling to eastern Canada tend to develop over the Rockies, the Great Lakes and the US East Coast. The ETCs are most intense over Newfoundland and the North Atlantic Ocean, confirming previous findings. While ETCs at cities along the Atlantic coastline (e.g. St. John's) are dominated by East Coast cyclones (which are intense in winter), those inland (e.g. Toronto) track primarily from the Great Lakes. ETCs that develop over the Gulf of Mexico affect eastern Canada infrequently, but those that do tend to be intense. The interannual variability of the wintertime ETCs is influenced by the El Niño-Southern Oscillation (ENSO). Significant ENSO-related variability is found over most regions of southern Canada, except on the east coast. Although ETCs at Toronto are significantly modulated by ENSO, no visible changes are found at St. John's. These ENSO-related ETC changes are mostly due to the shifts in ETC development regions, with minor changes in the travelling direction of ETCs.
\end{abstract}

KEY WORDS eastern Canada; ENSO; extratropical cyclones; synoptic climatology

Received 22 January 2014; Revised 20 August 2014; Accepted 21 August 2014

\section{Introduction}

The midlatitude climate and weather are modulated by successions of extratropical cyclones (ETCs) (Klein, 1951; Reitan, 1974). It was found that in some parts of North America, ETC activity may account for as much as $70 \%$ of the seasonal precipitation (Hawcroft et al., 2012). Given this important implication to the climate system (and more generally the water cycle), global and regional characteristics of ETCs have been extensively examined since the late 19th century. Recently, the future projection of ETC activity has also become of great interest (Bengtsson et al., 2009; Chang et al., 2012).

Many automated Lagrangian schemes for ETC detection and tracking have been developed to characterize seasonal, interannual and decadal variability of ETCs (Murray and Simmonds, 1991; Hodges, 1994; Sinclair, 1994; Serreze, 1995). These tracking algorithms have been applied to gridded reanalysis data (e.g. Hoskins and Hodges, 2002) and general or regional circulation model outputs (e.g. Notaro et al., 2006; Zappa et al., 2013) to examine the life cycles and tracks of ETCs. Although the large number of algorithms, designed for different purposes, causes a spread of the results between studies (Neu et al., 2013) there is general agreement that North American cyclones usually form over the lee of the Rockies or the US east

\footnotetext{
* Correspondence to: S.-W. Son, Bldg. 501, School of Earth and Environmental Sciences, Seoul National University, 1 Gwanak-ro, Gwanak-gu, Seoul 151-742, South Korea. E-mail: seok-woo.son@mcgill.ca
}

coast, travel northeastward and decay over Greenland, the Norwegian sea or Northwestern Europe. The seasonal and interannual variability of the North American cyclones is also well documented. For example, summer ETC tracks shift poleward and are more longitudinal in comparison to winter tracks (Klein, 1957; Zishka and Smith, 1980; Hoskins and Hodges, 2002). The southeastward shift of the ETC tracks during the positive phase of the El-Niño-Southern Oscillation (ENSO) is also well known (Eichler and Higgins, 2006; Grise et al., 2013). However, automated tracking algorithms have seldom been used to quantify the climatology and variability of ETCs at specific cities.

A few studies examining ETC activity over regional domains documented that ETC characteristics are regionally dependent. For example, Isard et al. (2000) examined ETCs across the Canadian and US Great Lakes and found seasonal cycles that are partly dependent on the latitudinal location of the cyclones' origin. Hirsch et al. (2001) isolated US east coast cyclones called 'Nor'easters' from other North American ETCs and documented that their frequency increases with latitude along the U.S. east coast. Regional details also emerged in the interannual variability of cyclone activity. In Canada, different teleconnection regimes were shown to be of varying dominance in different provinces, with ENSO dominating the cyclone variability in Ontario and Quebec (Wang et al., 2006) and the North Atlantic Oscillation (NAO) dominating that of the Atlantic provinces (Wang et al., 2006; Grise et al., 2013). 
Regional ETC activity has often been studied by tracking cyclones that are travelling from regions of frequent cyclogenesis (e.g. Alberta clippers, Colorado lows, Nor'Easters). Only a few studies have analysed how those cyclones affect the ETC activity at a location of interest, such as a specific city. A majority of these studies examined the local climate variability that directly impacts human activity, such as surface air temperature and precipitation variations (Archambault et al., 2008; Birk et al., 2010; Frankoski and DeGaetano, 2011). Although temperature and precipitation variations are intimately related to ETC activity, detailed characteristics of regional ETCs themselves are rarely investigated, especially over eastern Canada.

The goal of this study is to document the climatology and interannual variability of ETCs across eastern Canada. An automated tracking algorithm is used to identify and track cyclones over North America. A subset of ETC tracks that affect eastern Canada, especially Toronto and St. John's, is then examined in detail.

This paper is organized as follows. A short description of the data and methods is presented in Section 2. The seasonal mean properties of local cyclone activity are then documented in Section 3, followed by the interannual variability related to ENSO in Section 4. Summary and conclusions are presented in Section 5.

\section{Data and methods}

\subsection{Data}

The data used in the present study are taken from the 6-hourly data of the European Center for Medium-Range Weather Forecast Interim reanalysis (ERA-Interim) over the period of 1979-2009 (Dee et al., 2011). The wind speed and temperature that characterize the background flow are taken on pressure levels. However, as detailed in Grise et al. (2013), the relative vorticity fields, which are used in detecting and tracking ETCs, are taken on the hybrid sigma-pressure level closest to $850 \mathrm{hPa}$. To remove spurious noise, relative vorticity fields are filtered to the synoptic scale (wave numbers 5-42) before extracting ETC tracks as in Hoskins and Hodges (2002). While the $850-\mathrm{hPa}$ isobaric surface is often used for cyclone tracking (Hoskins and Hodges, 2002), the model level used in this study has the advantage of further reducing the tracking problems around high topography (Grise et al., 2013). It is shown in the Appendix that while most of the results are insensitive to this choice, growth rates on the lee side of the Rockies, where the $850-\mathrm{hPa}$ isobaric surface intersects topography, are somewhat sensitive to the choice of vertical coordinate. This, however, does not change the overall conclusions of the present study (see Appendix).

The interannual variability of local ETC activity is examined in the context of ENSO. The ENSO index is taken from NOAA's monthly El Niño Oceanic Index (ONI), which is a 3-month mean of Sea Surface Temperature (SST) anomalies in the Niño 3.4 region $\left(5^{\circ} \mathrm{N}-5^{\circ} \mathrm{S}\right.$, $120-170^{\circ} \mathrm{W}$ ) using ERSSTv3b data (Smith et al., 2008). For the 1979-2009 period, strong ENSO months are selected when the ONI exceeds \pm 1 standard deviation (STD). No time-lag was used on the ENSO index, as results were found to have a negligible sensitivity to the use of lags -1 and -2 months (not shown).

\subsection{Tracking algorithm}

A tracking algorithm developed by Hodges (1994, 1995, 1999) is used in this study to detect and track ETCs, which are essentially local maxima in the relative vorticity field. Since relative vorticity fields tend to be noisy, ETCs with very small intensities ( $<1$ cyclonic vorticity unit (CVU), or $1.0 \times 10^{-5} \mathrm{~s}^{-1}$ ) are omitted (see Appendix for the sensitivity to this threshold). The most realistic track ensemble is then selected using an iterative cost function that is based on a set of physical constraints (Hodges, 1999). This cost function takes into account the cyclone's former speed and position to constrain the succession of track points, keeping tracks with minimal velocity changes (speed or direction) instead of the classic nearest-neighbour approach. These constraints are adaptive to individual cyclone properties, e.g. less restrictive in direction changes for slower cyclones and more restrictive for fast moving cyclones commonly found at higher latitudes. The propagation speed (i.e. distance between two subsequent cyclone centres over a given time) is also limited according to the latitude of the cyclones, with a maximum upper bound displacement of six great circle degrees. Further details are discussed in Hodges (1994, 1995, 1999).

In this study, ETC tracks over the domain of $25-90^{\circ} \mathrm{N}$ are analysed if the cyclone centre (i.e. vorticity maxima) exceeds $1 \mathrm{CVU}$ for at least eight consecutive time steps (2 days) and travels at least $1000 \mathrm{~km}$. In this regard, a 'track' refers to the complete path of a given cyclone, while 'track point' refers to the individual cyclone detection point at any given time ' $t$ '.

\subsection{Cyclone properties}

ETC activity is characterized with the following track statistics:

- Cyclone frequency: Number of cyclone tracks that traverse a unit area per month (Klein, 1957; Colucci, 1976; Zishka and Smith, 1980).

- Cyclone intensity: Relative vorticity value (in CVU) at any track point.

- Cyclone growth and decay rates: For a cyclone detected at time $t$, the change in cyclone intensity (in CVU day ${ }^{-1}$ ) between time $t-1$ and time $t+1$ (over $12 \mathrm{~h}$ ).

- Direction of propagation: Direction (following meteorological convention) between cyclone positions at time $t-1$ and time $t+1$ (over $12 \mathrm{~h}$ ).

The cyclone frequency is the most consistent method to count the number of cyclones at a given location and insures that no cyclones are double-counted at any grid point. The cyclone frequency is qualitatively comparable 
to the 'track density' used by Hoskins and Hodges (2002). The above properties are binned in $1.5 \times 1.5^{\circ}$ boxes. To account for the synoptic scale, an area of ETC influence of $555 \mathrm{~km}$ radius (invariant with latitude) is assigned to each grid point. Statistics are then computed on these equal areas (hereby referred to as 'unit area', about $10^{6} \mathrm{~km}^{2}$ ) to avoid any latitudinal bias (Changnon et al., 1995). Except for cyclone frequency, all other statistics are defined only at the grid points where the mean cyclone frequency is higher than 0.3 cyclones per month.

\subsection{Analysis domains}

In this study, the region of specific interest is eastern Canada. In particular, ETCs that travel near Toronto and St. John's are examined in detail. Toronto is located close to the Great Lakes, far from the Atlantic coast. On the other hand, St. John's is the easternmost city of North America and is bordered by the Atlantic Ocean to the East and by the Gulf of St-Lawrence to the South. These geographical positions provide a good basis to characterize continental and maritime ETC activity across eastern Canada. The same analysis applied to other northeastern North American cities in fact shows an ETC climatology that resembles either that of Toronto or St. John's, or a blend of the two.

To select ETCs that impact these two cities, a radius of influence of $555 \mathrm{~km}$ is assigned to the exact location of each city (i.e. not at the closest grid point). The size of radius of influence is chosen to account for the synoptic-scale extent of ETCs, while being small enough to allow local characteristics to influence the climatologies. The results are not sensitive to the exact value of the radius of influence (see Appendix). The ETC tracks passing through these areas are then isolated to characterize the local ETC activity.

To isolate different types of ETCs, cyclone development regions are delimited in this study. Specifically, cyclones are grouped according to the region where they experience the maximum growth rate prior to their passage at the cities. Thus, growth and decay rates are used to determine cyclogenesis and lysis instead of the first and last cyclone track points, which is common in the literature (Hoskins and Hodges, 2002). This allows multiple growing and decay regions if the cyclone undergoes multiple life cycles. When cyclogenesis is considered specifically, only one region of genesis (or origin) is associated with each cyclone. If the re-development is more explosive than the earlier development, the re-development region is considered to be the cyclone's most relevant vorticity source. In case of a tie, the earliest development region is chosen. As discussed in Grise et al. (2013), this approach renders the geographical distribution of cyclogenesis and lysis to be less sensitive to the detection scheme and tracking parameters. In this analysis, we define 'local cyclone activity' as the collection of cyclone tracks that pass near a city of interest, and 'regional cyclone activity' as the collection of cyclone tracks that originate from a given development region.

\section{Climatology and seasonal cycles}

\subsection{North American ETCs}

The seasonal climatology of mean cyclone frequency and intensity over North America is presented in Figure 1. The mean winter cyclone frequency (top left) is highest over the lee side of the Canadian Rockies, the Great Lakes, Newfoundland and the North Atlantic. As continental cyclones tend to remain weak until they reach the Atlantic coast, the mean winter cyclone intensity is only maximized over Newfoundland and the North Atlantic Ocean. This contrasts with summer cyclone activity (third row), which features smaller cyclone frequency over the lee of the Rockies, and stronger intensity over Hudson Bay. It is also evident that the ETC tracks shift poleward during summer along with the jet stream, and that the region of maximum cyclone frequency becomes more longitudinal. During equinox seasons (second and bottom rows), ETC tracks are generally lower in frequency and more evenly distributed. All of these results are consistent with those documented in previous studies (Gyakum et al., 1989; Hoskins and Hodges, 2002; Mesquita et al., 2008).

Figure 1 also shows the regional differences in ETC activity. For instance, in the North Atlantic, the mean intensity of cyclones weakens in summer, but their frequency remains rather constant. In contrast, in Northern Canada, ETC frequency decreases in summer while the mean intensity increases, speculatively due to greater moisture supply from the ice-free Hudson Bay, documented to play a role in the strength of Hudson Bay polar lows (Albright and Reed, 1995). In the southern United States, the summer ETC activity is nearly absent both in frequency and intensity.

The seasonal cycle of ETC activity is highly associated with the seasonality of growth and decay of ETCs over different regions. The mean growth and decay rates of North American ETCs (Figure 2) are similar to those documented in previous studies (Gyakum et al., 1989; Hoskins and Hodges, 2002; Eichler and Higgins, 2006; Mesquita et al., 2008; Grise et al., 2013). The winter cyclone growth rate is strongest in the lee of the Rockies where lee cyclogenesis frequently occurs and along the U.S. east coast where the SST gradient is maximum. In summer, rapid cyclonic development largely disappears. However, this weakening in cyclone growth rate is not uniform, and regional variations are commensurate with the mean intensity changes in Figure 1. For example, cyclogenesis over the US east coast greatly weakens in summer. This contrasts with the almost constant cyclone development in the lee of the Canadian Rockies throughout the year, becoming the main region of summer cyclone development in North America. The Great Lakes region also shows weak growth rates throughout the year, but has a larger relative influence during the fall and spring seasons.

The regions of ETC dissipation (Figure 2, right column) exhibit a rather weak seasonal cycle in geographic distribution. Only mean magnitudes vary over the seasons, with the largest decay rates occurring in winter. Most Pacific cyclones decay near the west coast of Canada 

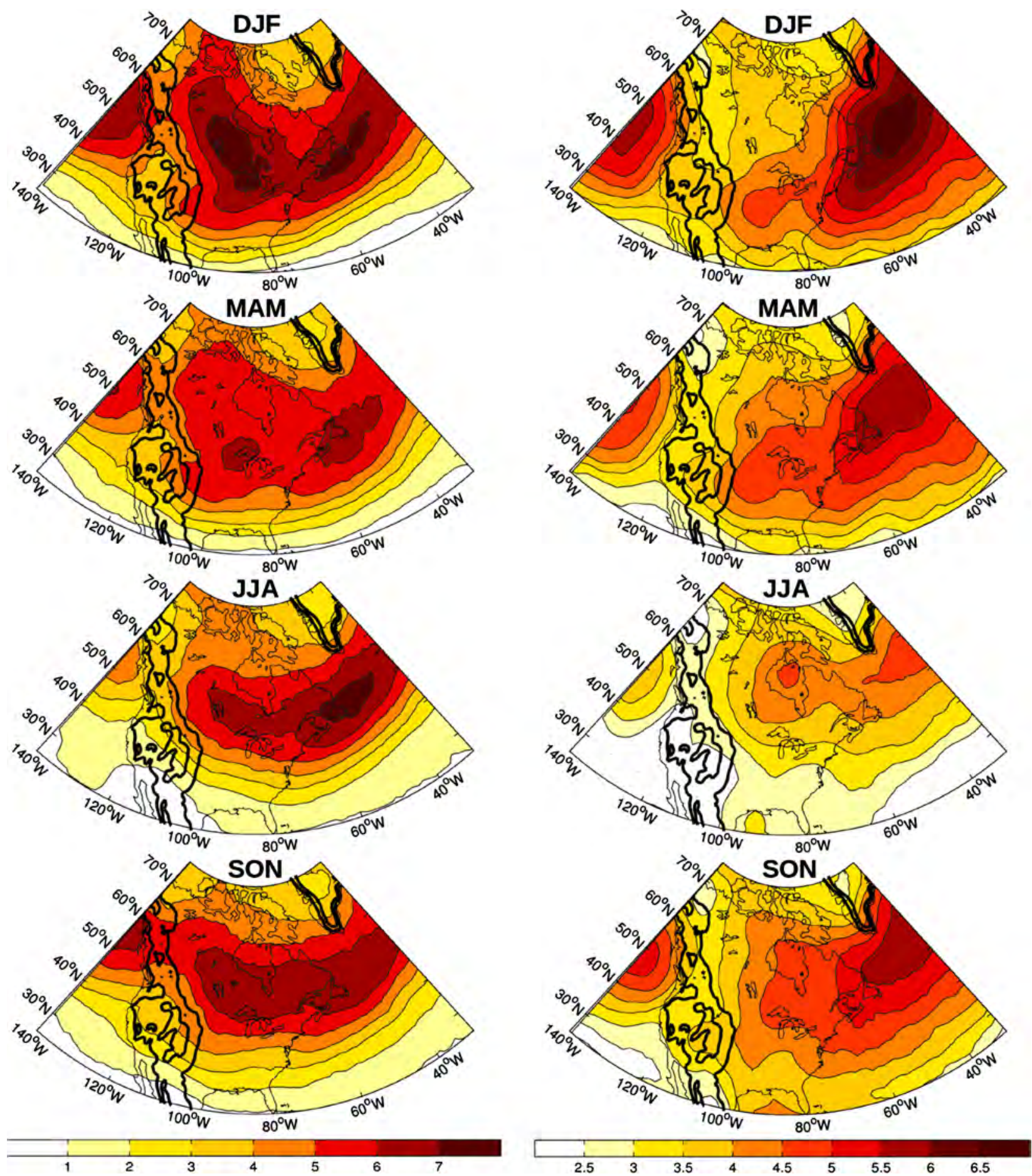

Figure 1. Climatological ETC frequency (left, in number of tracks per month) and intensity (right, in CVU) over North America for DJF, MAM, JJA and SON, binned on a $1.5 \times 1.5$ degree grid. Each grid box is assigned to a $555-\mathrm{km}$ radius region of influence, in which individual tracks can only be counted once. Regions where ETC frequency is $<0.3$ per month are excluded when computing ETC intensity. Thick solid lines denote topography with contour intervals of $1000 \mathrm{~m}$.

and United States, while continental ETCs decay in the Labrador Sea or the North Atlantic, close to Greenland. These results suggest that ETCs developing in the lee of the Rockies travel eastward, weaken over the northeastern Canada and dissipate near Greenland. Similarly, ETCs developing along the US east coast travel northeastward and dissipate near Greenland or the North Atlantic Ocean. These hypotheses are confirmed in Figure 3.
To examine the specific contribution of ETCs developing in different regions, North America is divided into six main regions of cyclone development: i.e. the Gulf of Mexico, Central Rockies, Northern Rockies, Great Lakes, East Coast and Hudson Bay. The tracks of ETCs that develop in these regions are presented in Figure 3. Cyclones developing in different regions show very different track distributions. ETCs developing in the South 

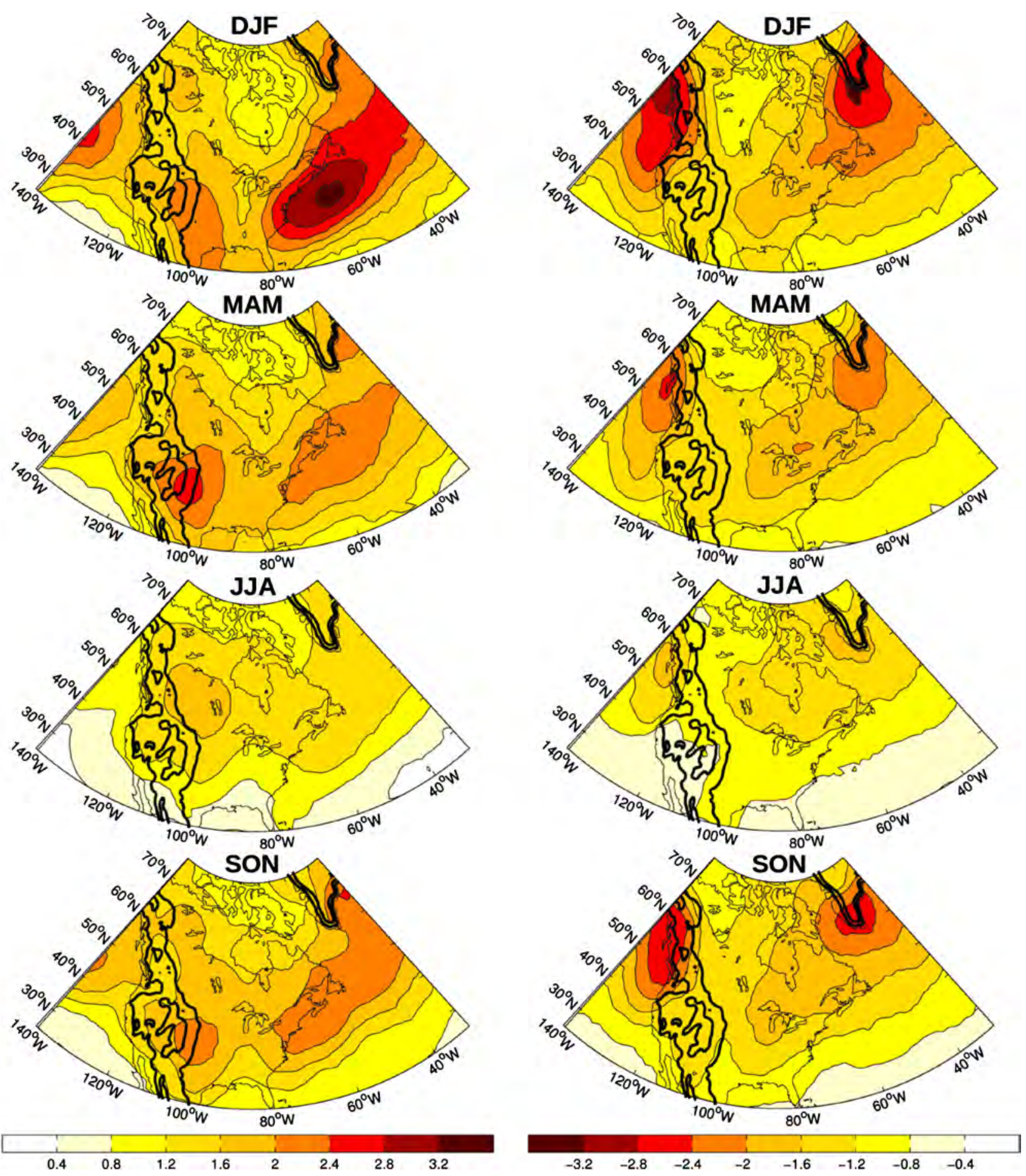

Figure 2. Same as Figure 1, but for ETC growth rate (left) and decay rate (right) in CVU day ${ }^{-1}$. Only points featuring cyclonic development ( $\geq 0$ $\left.\mathrm{CVU} \mathrm{day}^{-1}\right)$ are used in the growth climatology, and points featuring cyclonic dissipation $\left(\leq 0 \mathrm{CVU}\right.$ day $\left.^{-1}\right)$ are used in the decay climatology.

tend to have well-defined and consistent northeastward tracks (e.g. Gulf of Mexico and Central Rockies), while those developing in the North are rather scattered with southeastward or eastward propagation (e.g. Northern Rockies and Hudson Bay). The largest ETC frequency is observed along the US east coast due to strong cyclogenesis along the Gulf Stream (Figure 2, see also Grise et al., 2013). In general, the regional ETC tracks are similar to specific cyclone classifiers discussed in meteorological textbooks (e.g. Alberta clippers over the Northern Rockies and Nor'Easters over the East Coast), but they are not equivalent, as these specific types of cyclones are defined by more restrictive characteristics.

\subsection{ETCs across eastern Canada}

To characterize the ETC activity across eastern Canada, the local cyclone activity at Toronto and St. John's is 

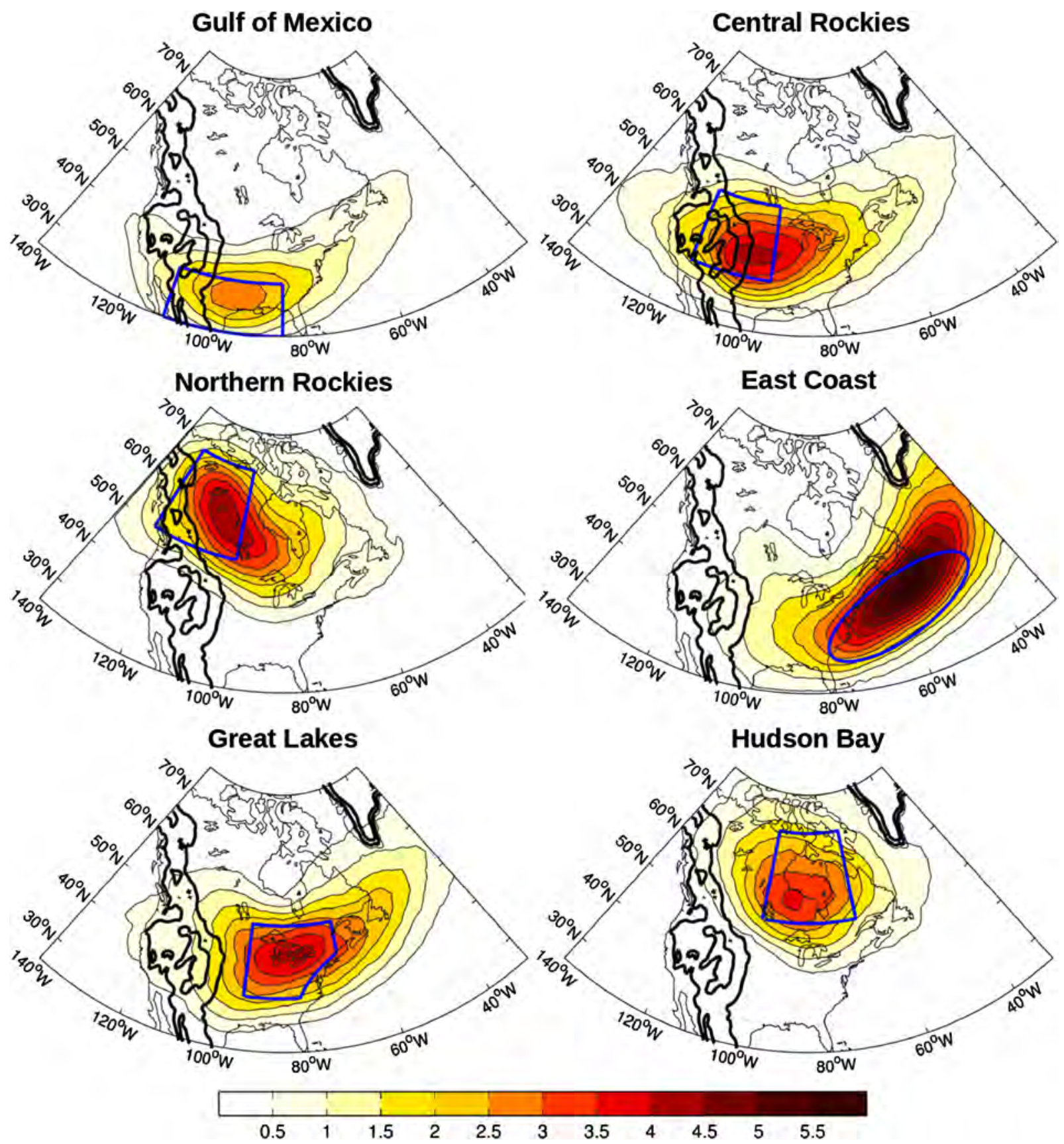

Figure 3. Winter ETC frequency for each cyclone development region. Only the tracks of ETCs that experience maximum growth in the region of interest are used in the computation.

closely examined in this section. The typical ETCs travelling near the two cities are presented in Figure 4. Toronto's cyclones tend to track from the Rockies to the Great Lakes region, travelling west to east, whereas most cyclones that impact St. John's travel along the Atlantic coastline from the Southwest. The mean intensity of the ETCs (shading, bottom row) reveals a tendency for the cyclones to remain weak until they reach the Atlantic coast, with stronger cyclones around St. John's than around Toronto. While St. John's cyclones mainly feature quick intensification over the East Coast, Toronto's cyclones show more complex life cycles with a local minimum in mean intensity around $80^{\circ} \mathrm{W}$.
Figure 5 features the 6-hourly tracks of the 25 most intense ETCs that pass through the regions of Toronto and St John's along with their composite evolution of relative vorticity, wind speed and mean sea level pressure (MSLP). Here, lag 0 indicates when each ETC is located closest to Toronto or St. John's, and relative vorticity and wind speed are evaluated on the hybrid sigma-pressure level near $850 \mathrm{hPa}$, where the ETC tracking is performed. It is evident from Figure 5 that these intense ETCs typically have a single life cycle with a maximum value of relative vorticity shortly after lag 0 . Although some of Toronto's intense ETCs re-intensify in time as they approach the Atlantic (top left panel), the relative vorticity of most of 

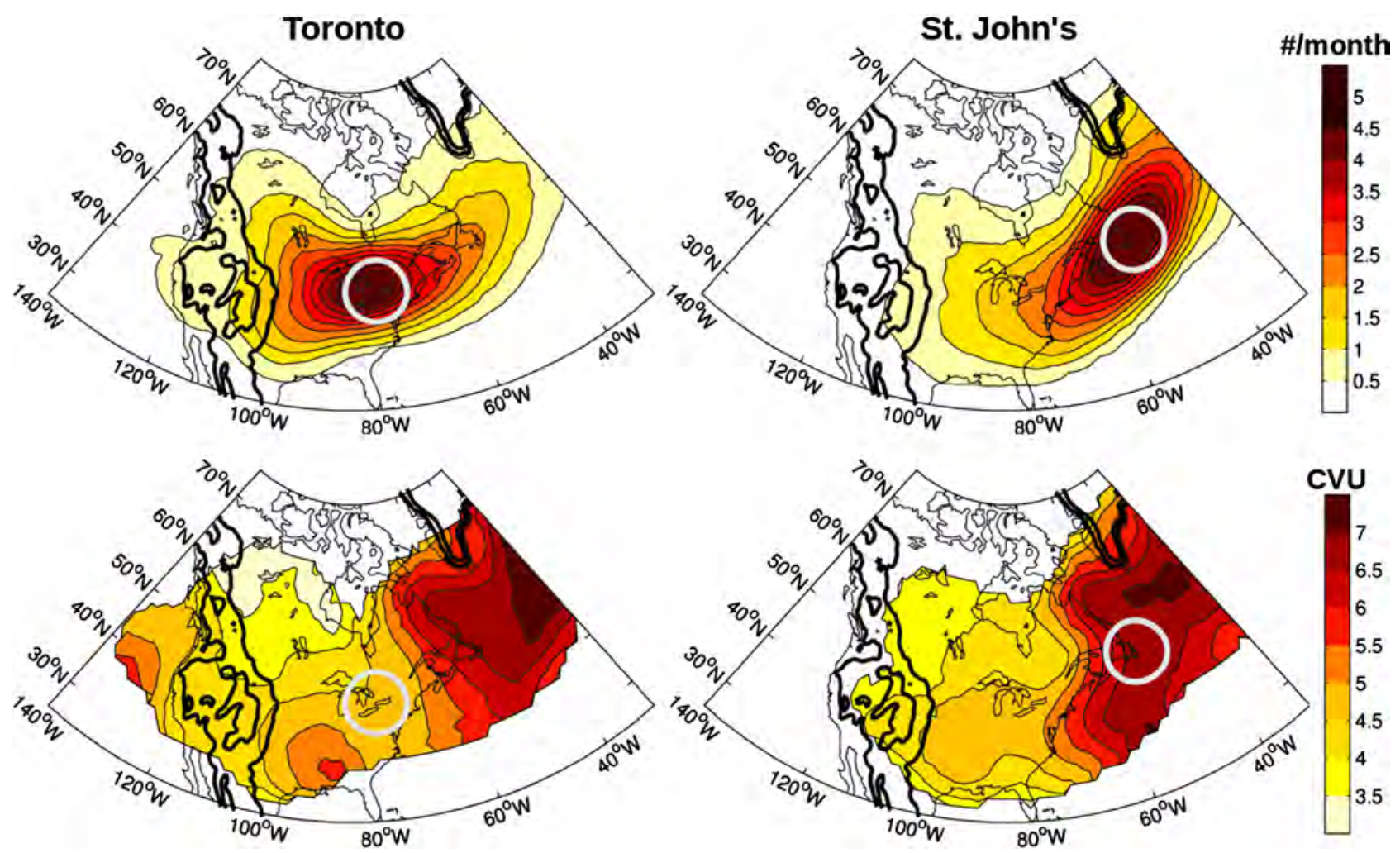

Figure 4. Cyclone frequency (top, in number of tracks per month) and mean intensity (bottom, in CVU) of winter ETCs across Toronto (left) and St. John's (right). The area of interest is indicated by a thick circle.

the intense cyclones decays after passing through Toronto. This indicates that the mean intensity of all of Toronto's ETCs, which is maximized over the Atlantic (bottom left panel of Figure 4), is mostly due to the cyclones that are rather weak near Toronto and develop later.

The most intense ETCs over Toronto's region reach a maximum relative vorticity of $\sim 9$ CVU, an MSLP of $\sim 990$ $\mathrm{hPa}$ and a maximum wind speed of $16 \mathrm{~ms}^{-1}$ at lag 0 . The growth rate of these cyclones is rather gradual as they are already quite intense at $\mathrm{lag}=-48 \mathrm{~h}$ (i.e. $4-5 \mathrm{CVU}$ intensification in 2 days). Interestingly, while the relative vorticity of these cyclones weakens shortly after lag 0 , their wind speed and MSLP continue to intensify as they approach the East Coast, reaching a maximum of $\sim 24$ $\mathrm{ms}^{-1}$ and a minimum of less than $985 \mathrm{hPa}$, respectively, more than $24 \mathrm{~h}$ after lag 0 . This suggests that the spatial scale of the ETCs increases in time as they continue northeastward towards the Atlantic.

St. John's severe cyclones are much more intense in comparison to those over Toronto. While Toronto's most intense cyclones showed substantial intensity long before their passage through the city (about 5.5 CVU at lag $-48 \mathrm{~h}$ ), St. John's cyclones only start growing over the Atlantic, relatively close to the city (about 3.5 CVU at lag $-48 \mathrm{~h}$ ). Their composite relative vorticity, wind speed and MSLP reach $\simeq 12 \mathrm{CVU}, 30 \mathrm{~ms}^{-1}$, and less than $965 \mathrm{hPa}$, respectively, soon after lag 0 . More importantly, their composite relative vorticity grows and decays much faster than Toronto's intense ETCs (almost twice as fast). Their wind speed and MSLP weaken after lag 0, although the decay rates are slower than the decay rates of relative vorticity, also suggestive of an increase in scale as the cyclones travel northward. These differences in intensity, wind and life cycle between Toronto and St. John's most intense cyclones are indicative of the different physical properties between intense coastal cyclones (e.g. those near St. John's) and relatively strong continental cyclones (e.g. those near Toronto). The dynamics of the stronger coastal cyclones are distinguished from those of the continental ETCs in several ways. The coastal cyclones are stronger, and grow faster, because of their proximity to the relatively warm ocean (particularly during their cold-season peak frequencies), their relatively weak stratification and reduced roughness as compared with the continental environment. The interannual variability of the continental and coastal cyclone track and intensity may be influenced differently by low-frequency patterns such as ENSO, as will be discussed in the next section.

Characteristics of ETCs affecting the two cities are further illustrated in Figure 6. Windrose distributions are used to illustrate the directions from where the ETCs travel, and colours are used to denote the intensity of the cyclones. During winter, an average of 6.6 (STD of 1.6) cyclones per month travel across Toronto's region (Figure 1), typically travelling from the west with an intensity of 2-6 CVU and occasionally reaching a maximum intensity of $10 \mathrm{CVU}$ (top left panel of Figure 6). The track direction shows little seasonal cycle. In contrast, St. John's cyclones are more intense and predominantly come from the Southwest (top right). An average of 7.1 (STD 

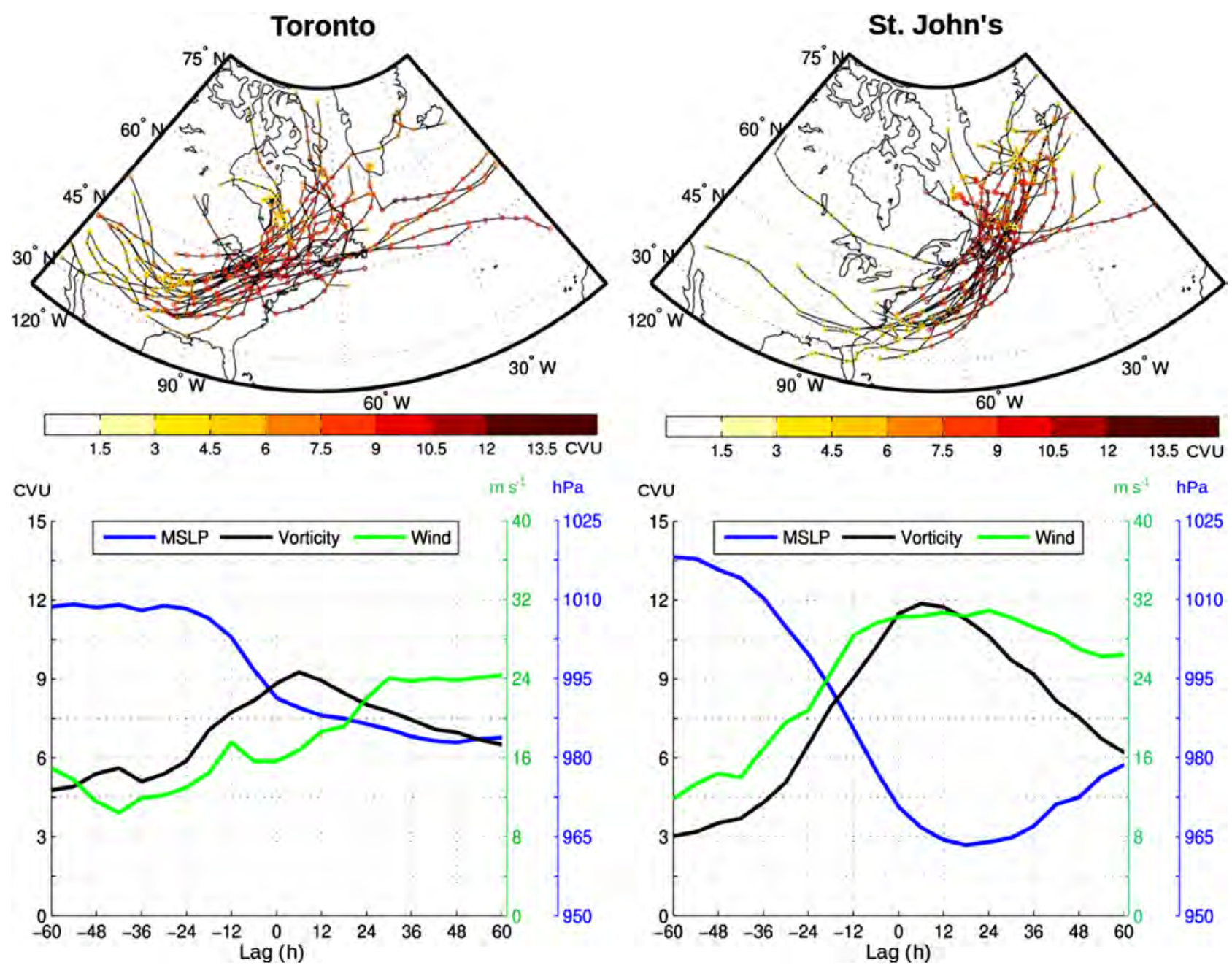

Figure 5. Composite evolution of the top 25 most intense cyclones at Toronto (left) and St. John's (right) regions. Top: 6-hourly ETC tracks are shown in lines with their central location (dot) and intensity (colour, in CVU). Bottom: Composite relative vorticity (CVU), wind speed (in $\mathrm{m} \mathrm{s}^{-1}$ ), and MSLP (in hPa) are shown as a function of time. Relative vorticity and wind speed are computed at the hybrid sigma-pressure level near $850 \mathrm{hPa}$,

where the ETC tracking is performed. On the abscissa, lag 0 denotes the time when the ETCs are located closest to Toronto or St. John's.

of 1.1) cyclones are observed in winter, with a typical intensity between 6 and $10 \mathrm{CVU}$, the maximum intensity exceeding $12 \mathrm{CVU}$. In both cities, cyclones travelling from the southwest are generally more intense than the others, as they approach the polar jet stream along their track. This relationship is more important for St. John's, as the ETCs further benefit from the warm Atlantic Ocean. During summer, track directions show little change (third row of Figure 6), with only a slight change observed for St. John's cyclones (e.g. about 25\% of St. John's ETCs travel from $180^{\circ}-225^{\circ}$ in winter vs. about $12 \%$ in summer). The number of ETCs decreases in summer in Toronto (5.6 (STD of 1.2) cyclones per month), and the mean intensity becomes weaker in summer in both cities.

Figure 4 suggests that the local ETC activity is influenced by cyclones that develop and travel from various regions. To examine this, cyclones travelling to Toronto and St. John's are grouped according to their development regions and binned in number and intensity (Figure 7). Although there is a dominant cyclone development region for each city (e.g. the Great Lakes for Toronto and the
East Coast for St. John's), ETCs crossing each city originate from multiple development regions. Although these development regions are carefully selected to include most ETCs' origins, some cyclones form outside of the six selected development regions. Specifically, 5\% of Toronto's and 13\% of St. John's ETCs originated from other regions.

A significant number of ETCs travelling to Toronto form over the Central Rockies and the Great Lakes regions, peaking in number at an intensity of $4 \mathrm{CVU}$ in most seasons (left column of Figure 7). There is a substantial contribution to Toronto's cyclones from the Northern Rockies and the Hudson Bay development regions in winter, although these cyclones rarely get stronger than $8 \mathrm{CVU}$. Toronto is also affected by cyclones developing close to the Gulf of Mexico. Although not as numerous, they peak at about $7 \mathrm{CVU}$, representing a significant fraction of Toronto's intense winter cyclones. In St. John's, cyclone activity is largely dominated by East Coast cyclones and their strong seasonal cycle (right column of Figure 7). The number of East Coast cyclones 

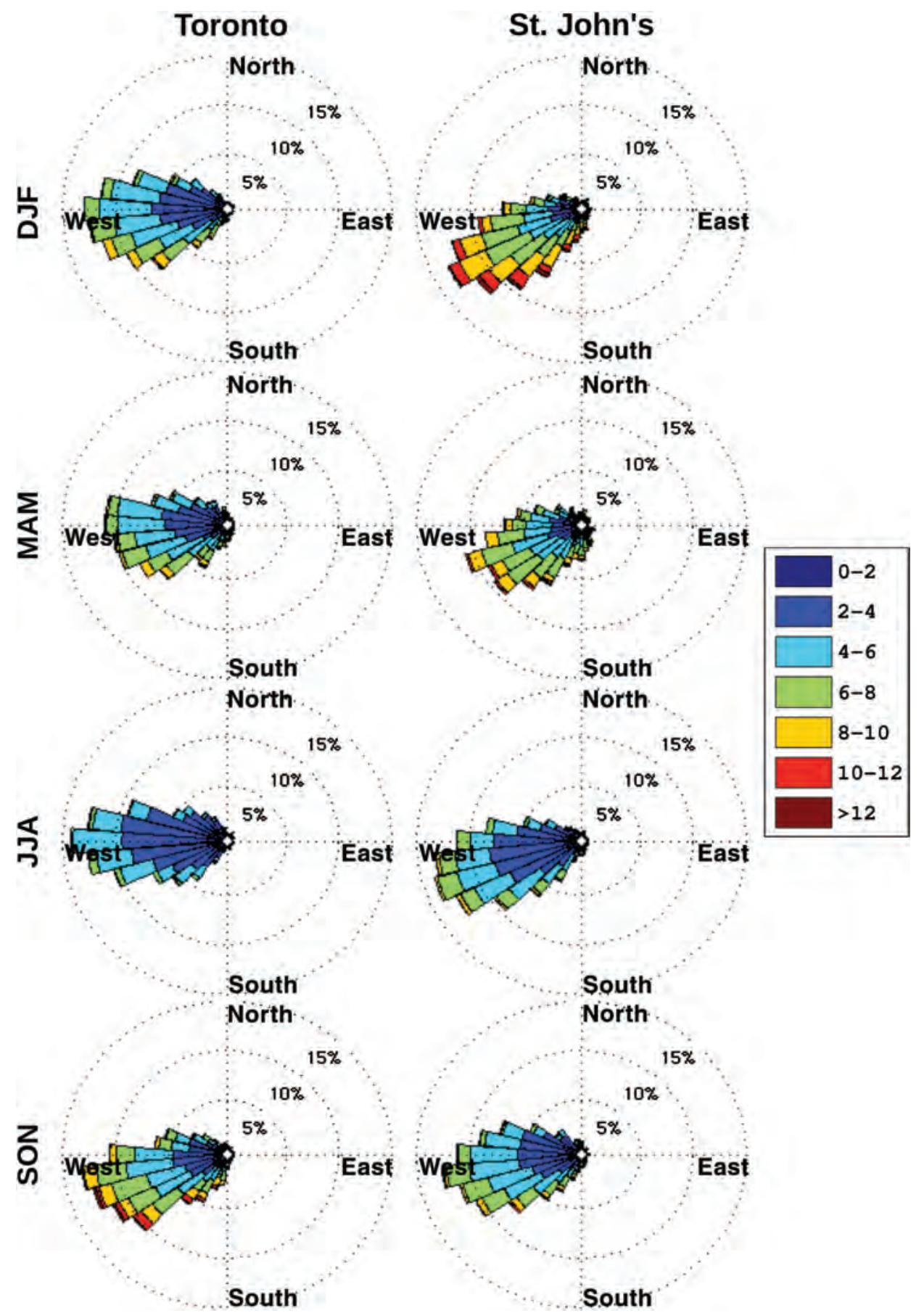

Figure 6. Seasonal distribution of Toronto and St. John's ETCs in terms of intensity (colour, in CVU) and travelling direction. Bars extend towards the direction that cyclones are coming from. The length of the bars is proportional to the percentage of cyclones found in each category. Dotted circles indicate $5 \%, 10 \%$ and $15 \%$ of the total number of cyclones.

that approach St. John's peaks at an intensity of $6 \mathrm{CVU}$ in winter (see also Figure 4), but only at $3 \mathrm{CVU}$ in summer. This strong seasonality is also evident in their travelling direction. In summer, the relative number of continental cyclones (from the Great Lakes) increases at St. John's, consistent with the seasonal shift in ETC travelling direction (see Figure 6). These results, which differ from Toronto's cyclone activity, suggest that the local ETC activity in eastern Canada is highly dependent on location. Grise et al. (2013) in fact showed that while Toronto's cyclone activity is affected by the Pacific North American teleconnection (PNA) on intra-seasonal timescales, St. John's cyclone activity is more or less modulated by a teleconnection similar to the NAO.

\section{Interannual variability associated with ENSO}

This section examines the impact of ENSO on the North American ETC activity, focusing on those travelling over the regions of Toronto and St. John's. Here, ENSO years 

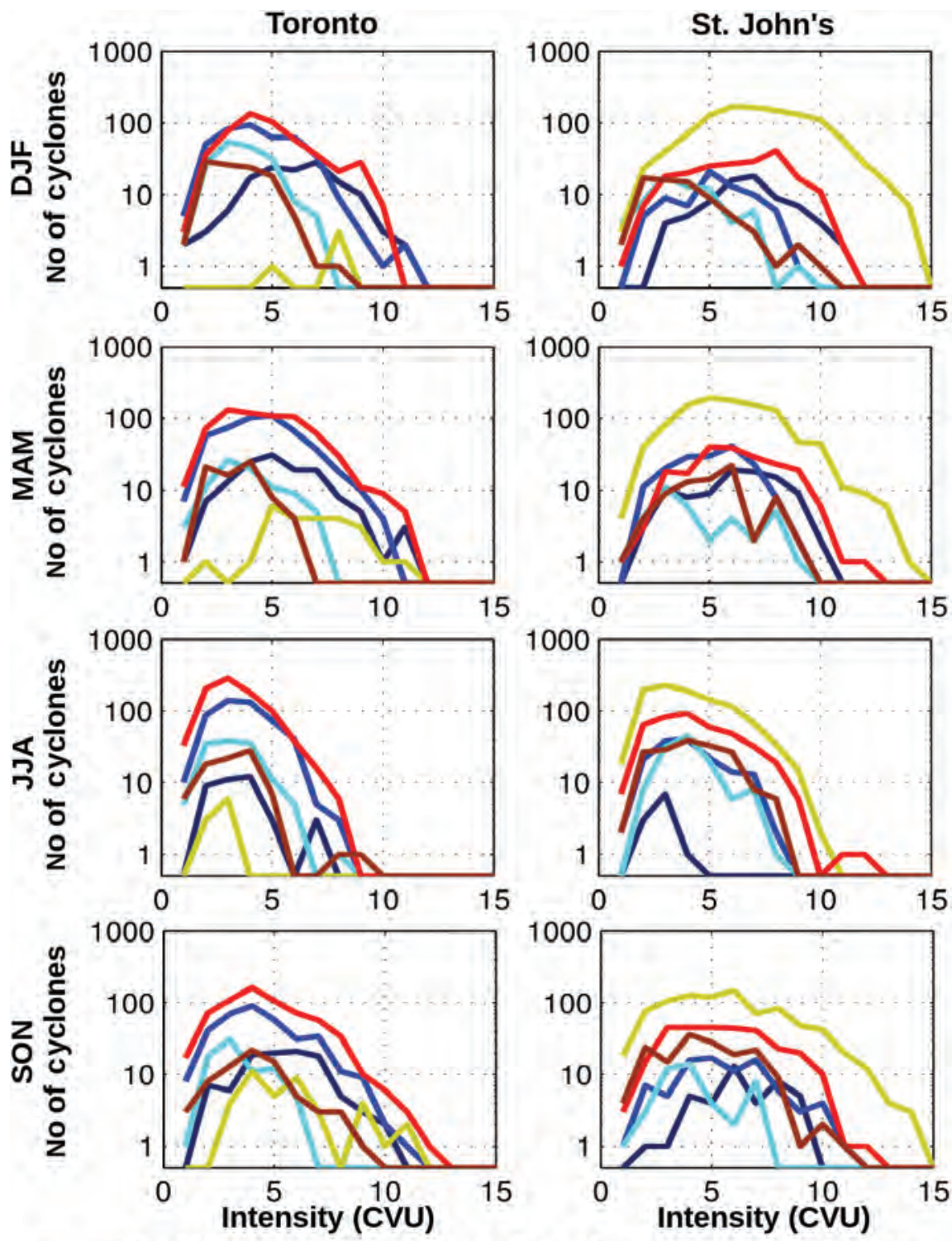

G. of Mexico

East Coast
Central Rockies

Great Lakes
N. Rockies

Great Lakes

Figure 7. ETC statistics in terms of cyclone development regions for Toronto (left) and St. John's (right). Vertical axis denotes the number of cyclones, and horizontal axis denotes the intensity of cyclones.

are selected when the ONI is greater or less than 1 STD (see Section 2). As the climatological ETC activity is seasonally dependent, the impact of ENSO on cyclone activity varies considerably between seasons. However, for conciseness, only the winter season [from December to February (DJF)], during which the ENSO is known to exert a larger influence on the Canadian weather (Shabbar and Barnston, 1996), is presented. Figure 8 presents the composite anomalies of 250-hPa wind, ETC frequency and mean intensity for each phase of ENSO. Values that are statistically significant at the $95 \%$ confidence level are shaded in colour. During the negative phase of ENSO (-ENSO), the westerly jet shifts poleward and become more longitudinal, with a dipole anomaly about the axis of the climatological jet especially at the jet entrance region. The opposite pattern is observed during the positive phase of
ENSO (+ENSO), with broader and stronger mid-latitude westerly anomalies than during -ENSO years. This subtle difference is due to slight asymmetry between the two phases of ENSO and the related teleconnection patterns.

The ENSO-related ETC frequency anomaly closely resembles the $250 \mathrm{hPa}$ wind speed anomaly, highlighting the dependence of ETC activity to the Atlantic westerly jet position. During + ENSO winters, ETC frequency significantly increases over the Southern U.S. but decreases at higher latitudes, indicating an equatorward shift of the ETC tracks. The equivalent and opposite pattern is also observed during -ENSO winters with a significant decrease in ETC frequency over the Gulf of Mexico. These results are largely consistent with previous findings (e.g. Eichler and Higgins, 2006). Interestingly, the ETC frequency over northern Quebec exhibits negative 

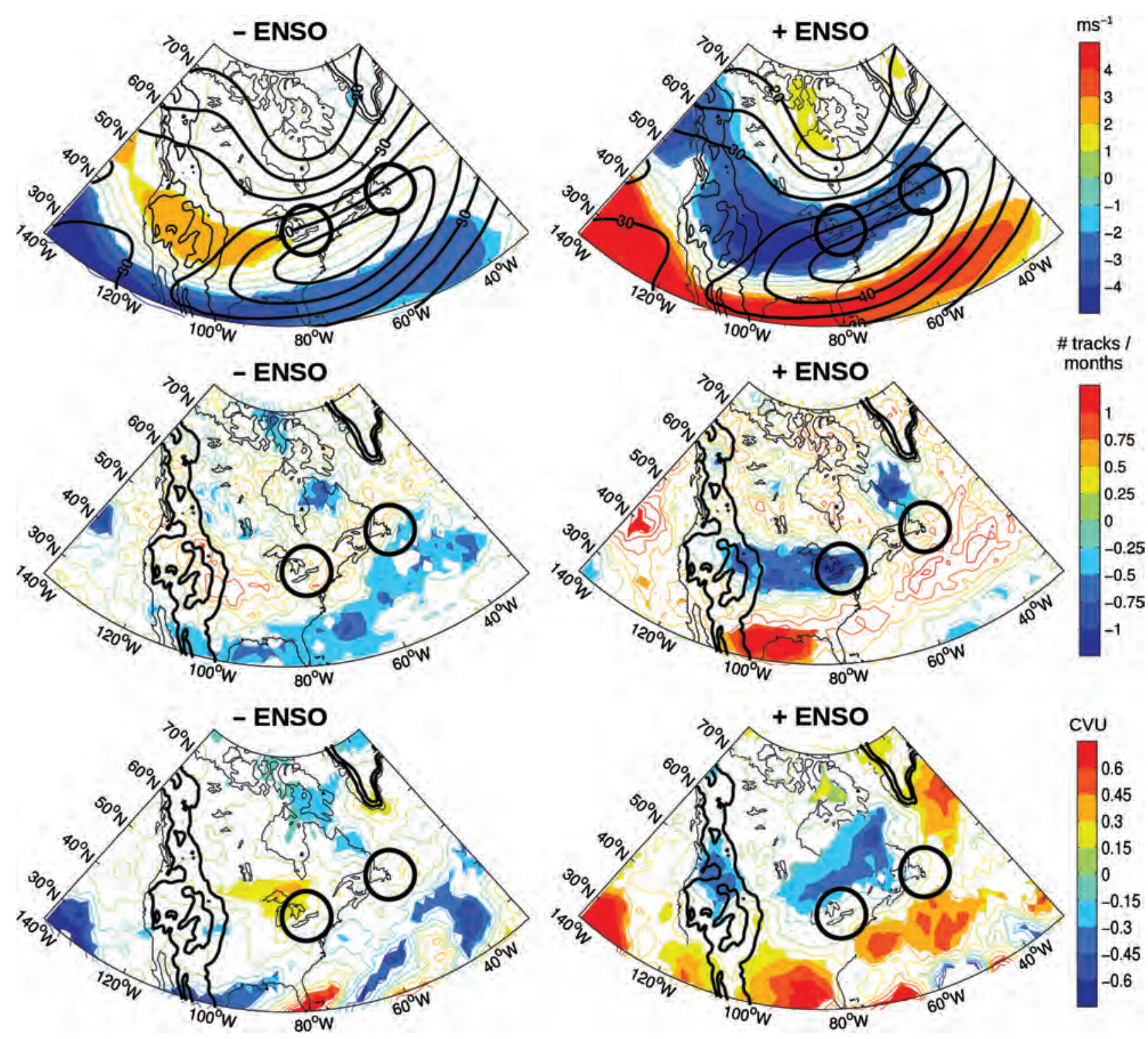

Figure 8. Top: DJF wind speed anomaly at $250 \mathrm{hPa}$ (top, in $\mathrm{m} \mathrm{s}^{-1}$ ), ETC frequency anomaly (middle, in number of cyclones per month) and ETC intensity anomaly (bottom, in CVU) during ENSO months. Thick contours indicate the climatology in contour intervals of $10 \mathrm{~m} \mathrm{~s}^{-1}$. Shading indicates the values that are statistically significant at the 95\% confidence level. For reference, Toronto and St. John's regions are indicated by thick circles.

anomalies during both phases of ENSO. This is caused by different responses of regional ETC tracks to ENSO, as discussed later in this section.

The mean intensity change of ETCs with ENSO phases is presented in the bottom row of Figure 8. Significant changes are evident over the Atlantic and northeastern North America. The equatorward shift in cyclone tracks during +ENSO winters is generally associated with anomalously strong cyclones in the Gulf of Mexico and along the US East Coast and anomalously weak cyclones at mid- and high-latitudes. In contrast, the mean intensity change of continental ETCs is rather weak during -ENSO years.

The ETC frequency anomaly associated with -ENSO and +ENSO are detailed in Figures 9 and 10, respectively. In these figures, individual ETCs are grouped into their development regions. It is found that the latitudinal shift of the ETC tracks during ENSO winters does not result from a latitudinal shift of all types of ETC tracks. In general, the frequency of ETCs from the Central Rockies and the Great Lakes significantly decreases during +ENSO, but the frequency of ETCs from the East Coast and the Gulf of Mexico increases (vice versa during -ENSO). This pattern has often been described as an ENSO-related oscillation between continental and maritime cyclones (Noel and Changnon, 1998; Hirsch et al., 2001; Bradbury et al., 2003), implying that local ETC activity across eastern Canada is likely determined by the competition between continental and maritime cyclones.

The response of regional ETC frequency is not always opposite during the two phases of ENSO. For example, while the frequency of ETCs developing over the Central Rockies increases only slightly during -ENSO winters, 

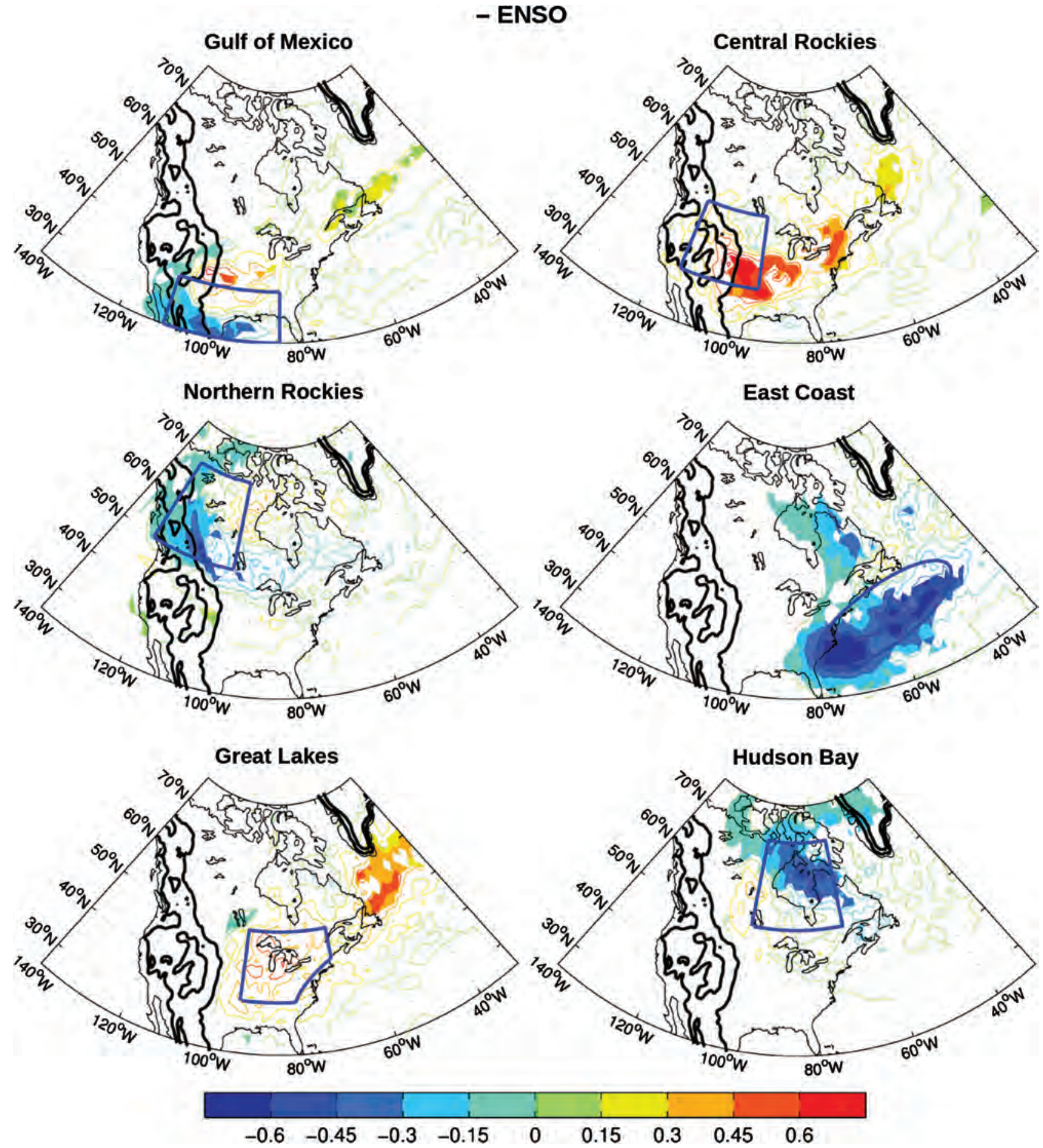

Figure 9. ETC frequency anomaly (in number of cyclones per month) in terms of development regions during -ENSO.

it decreases substantially over a broader region during +ENSO winters. Additionally, while ETCs developing over the Great Lakes experience no significant change during -ENSO winters, they significantly decrease in frequency during +ENSO winters. The decrease in frequency of ETCs developing over the Central Rockies and the Great Lakes (Figure 10) causes the ETC frequency over northern Quebec to be anomalously low during +ENSO winters (middle row of Figure 8), even though ETCs developing over the Hudson Bay are more frequent. In contrast, during -ENSO winters, the negative anomalies observed over Northern Quebec are mostly due to the reduced frequency of ETCs from Hudson Bay and the East Coast, with a negligible contribution from Great Lakes ETCs (Figure 9). These results suggest that ENSO-induced ETC variability is not symmetric between the two phases at regional scales. These results also indicate that local ETC activity can be significantly modulated by the changes in ETCs that develop in remote regions. 

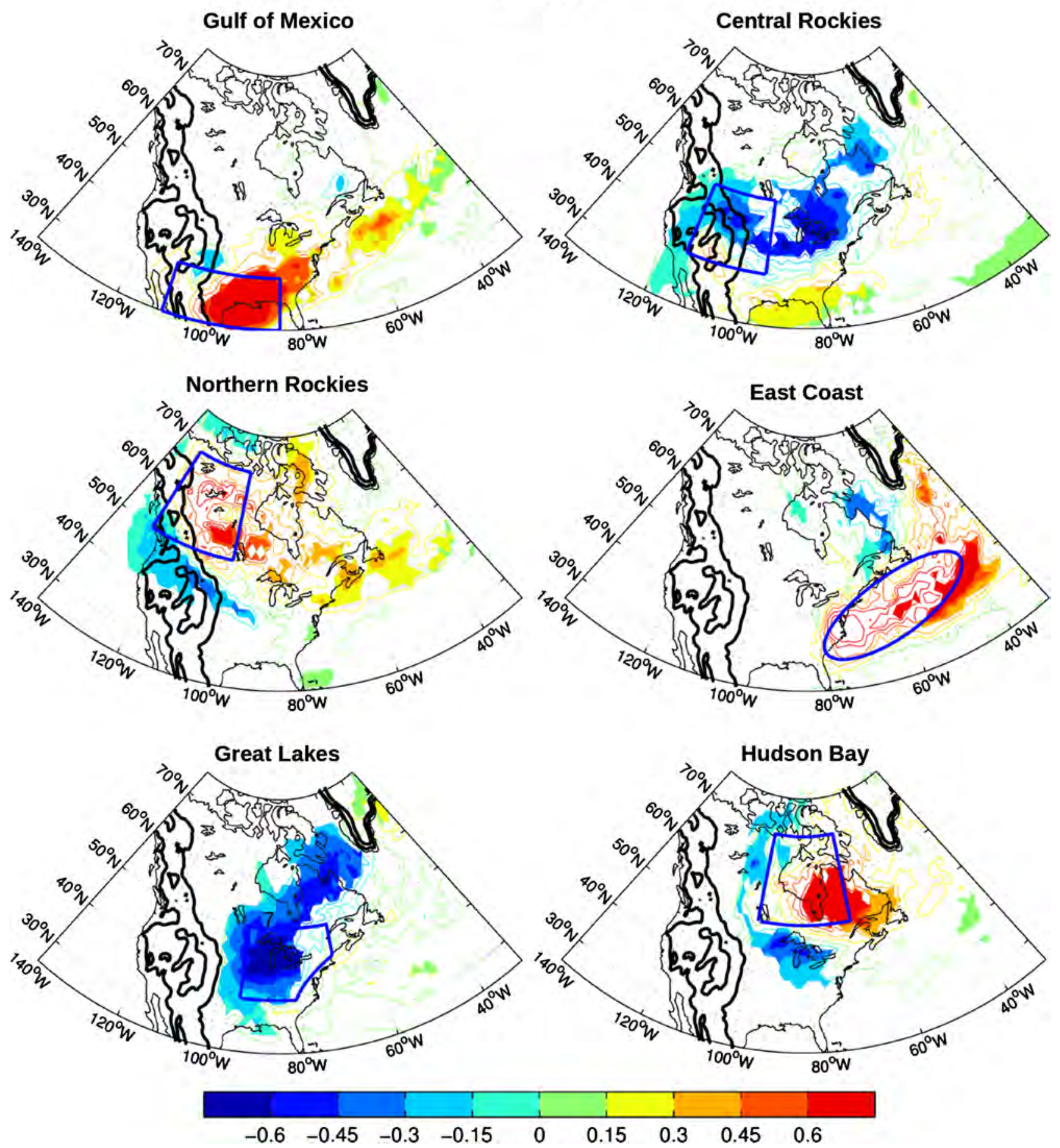

Figure 10. ETC frequency anomaly (in number of cyclones per month) in terms of development regions during +ENSO.

The ETC activity near Toronto and St. John's is only marginally affected by ENSO, as shown in Figure 8. Nonetheless, for Toronto, important interannual variability is observed when the development regions are taken into account. Figure 11 shows the frequency, intensity and travelling direction of ETCs tracking close to Toronto during ENSO winters. For reference, the climatology is shown in the thick empty bars. As discussed in the previous section, most of the ETCs travelling across Toronto's region form in the Great Lakes (2.5 cyclones per month, STD of 0.9 ) and the Central Rockies (1.9 cyclones per month, STD of 0.6) regions. ETCs from other regions are more sporadic, with 0.75 from the Northern Rockies (STD of 0.7), 0.6 from the Gulf of Mexico (STD of 0.4) and 0.5 from Hudson Bay (STD of 0.5$)$. The missing portion $(\leq 0.5$ cyclones per month) represents weak cyclones developing outside of the six regions defined in Figure 3.

Although the total number of ETCs at Toronto does not change much during -ENSO winters (Figure 8 middle left), a noticeable change is observed in their development 

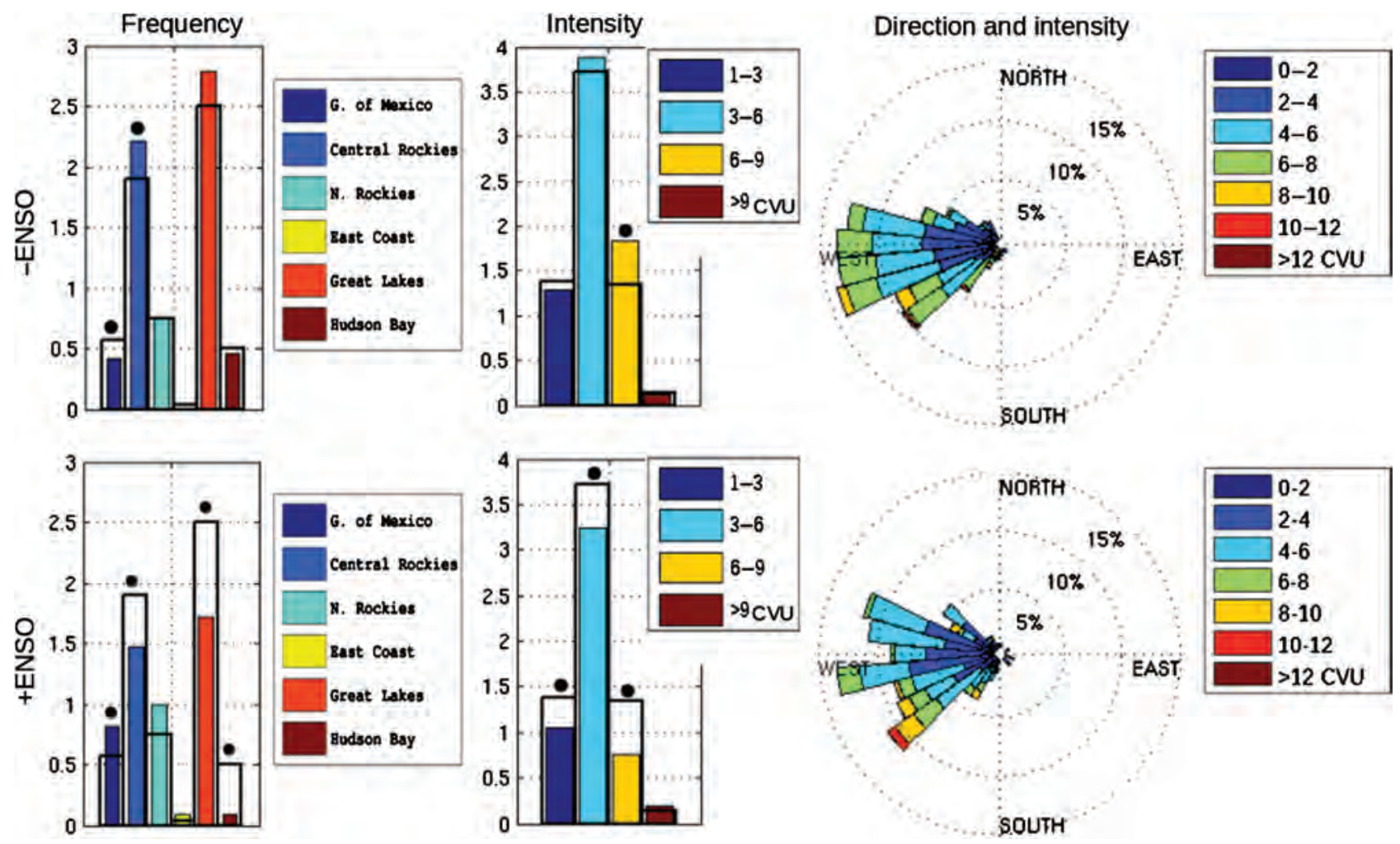

Figure 11. Frequency (left, in number of tracks per month), mean intensity (middle, in CVU) and travelling direction (right column) of Toronto's winter cyclones from each development region during ENSO (coloured bars) along with the long-term climatology (thick, empty bars). The difference between the coloured and empty bars represents the anomaly associated with the given development region and the anomalies that are statistically significant at the $90 \%$ confidence level are indicated by dots.

regions. For example, a smaller number of ETCs track from the Gulf of Mexico, while more cyclones travel from the Central Rockies, consistent with the changes in cyclone development shown in Figure 9. The mean intensity of Toronto's cyclones slightly increases during -ENSO (Figure 8 bottom left). This is mainly due to an increase in the number of strong cyclones during -ENSO (about $30 \%$ more cyclones $\geq 6 \mathrm{CVU}$ than normal). During +ENSO winters, Toronto's cyclone frequency decreases (Figure 8 middle right), mostly due to the reduction of ETCs from its two predominant development regions (Central Rockies and Great Lakes) and the Hudson Bay. This decrease is partly compensated by an increase in the frequency of ETCs from the Gulf of Mexico. In general, the mean intensity of ETCs is weaker than normal because of the reduced number of ETCs from the Central Rockies and the Great Lakes, which are generally strong over Toronto (Figure 7). It is also found that the travelling direction of ETCs does not change much (right column of Figure 11), simply reflecting ETC changes from different regions with a wider spread during + ENSO years.

In contrast to Toronto's cyclone activity that is largely controlled by continental cyclones, St. John's cyclone activity is dominated by East Coast ETCs. Because East Coast ETCs that propagate Northward are less sensitive to ENSO than continental ETCs, the ENSO-related interannual variability of St. John's cyclones is rather weak (Figure 8). Indeed, no significant ENSO-related changes in ETC frequency and intensity are observed.

\section{Summary and conclusions}

The characteristics of North American ETCs are examined with a focus on the regional climatology and interannual variability over Eastern Canada, particularly near two cities: Toronto and St. John's. The automated detection scheme developed by Hodges (1999) is applied to the vorticity field taken from ERA-Interim's hybrid sigma-pressure level closest to $850 \mathrm{hPa}$ over the 1979-2009 time period (Grise et al., 2013). ETC statistics such as cyclone frequency, mean intensity, growth, decay, and travelling speed and direction are quantified. Unlike previous studies, ETC tracks are also grouped according to their development (or genesis) regions, defined as the region in which the most explosive growth occurred along any given track.

It is found that ETCs that form in different regions have different characteristics. The cyclones developing along the US East Coast are typically strong and most frequent during winter, as rapid growth is favoured by high baroclinicity due to strong land-sea contrasts and SST gradients. The mean intensity of East Coast cyclones, however, becomes significantly weaker in summer. A similar seasonality is also observed for ETCs developing 
over the Gulf of Mexico and Southern U.S. with almost no ETCs in summer due to the poleward shift of the westerly jet. The ETCs originating from the Central Rockies and the Great Lakes, however, tend to have a rather weak seasonality with a maximum frequency in equinox seasons, when continental cyclones are favoured by the highly variable jet between the Rockies and the East Coast. Lastly, the cyclones developing at high latitudes (Northern Rockies or Hudson Bay regions) are found to be weak and more frequent in the summer. In terms of travelling direction, it is also found that while the ETCs developing over the central Rockies, Great lakes, Gulf of Mexico and East Coast travel northeastward along the westerly jet, those developing over the Northern Rockies and Hudson Bay travel eastward or southeastward.

The above regional characteristics of ETCs have a significant influence on cyclone activity over Eastern Canada. This is anticipated because most of the continental and some of the East Coast ETCs travel towards Eastern Canada and dissipate there or close to Greenland. While the most important cyclones (in terms of number of cyclones) to Eastern Canada are those developing over the Central Rockies and the Great Lakes, cyclones from other regions also play a non-negligible role, especially in the seasonal cycle. For example, ETCs developing over the Gulf of Mexico and Southern U.S. typically do not travel to the Eastern Canada, but those that do are a significant source of intense winter cyclones $(>10 \mathrm{CVU})$

Local characteristics of ETCs in Eastern Canada are further investigated for the regions of Toronto and St. John's. Toronto is found to be predominantly influenced by ETCs from the Great Lakes and the Central Rockies, with rather small variations in ETC frequency and intensity between seasons, except for a significant decrease in ETC intensity in summer. Although not shown, a similar result is also found for Montreal and Quebec city. In contrast, the activity of ETCs travelling across St. John's region is predominantly influenced by East Coast cyclones, which exhibit a significant seasonal cycle with larger frequency and mean intensity in winter.

The interannual variability of the ETC tracks is determined by the combined effect of various regional cyclones. The ENSO oscillation between continental and coastal cyclones is confirmed, with an increase in the frequency of ETCs developing over the Gulf of Mexico and the East Coast but a decrease in the frequency of those developing over the Central Rockies and the Great Lakes during + ENSO winters. The opposite is largely true for -ENSO winters. Interestingly, ETC frequency around northern Quebec decreases during both phases of ENSO. This negative anomaly is caused by the reduced frequency of ETCs developing over the East Coast and Hudson Bay during -ENSO winters and the reduced frequency of ETCs travelling from the Central Rockies and the Great Lakes during + ENSO winters.

Specifically, ENSO-related ETC variability is observed at Toronto. The frequency and the mean intensity of
Toronto's ETCs decrease in +ENSO winters as the westerly jet shifts equatorward. Even if the total number of ETCs found close to Toronto does not change much, their origin and mean intensity are modulated by \pm ENSO, possibly resulting in different surface weather. No significant ENSO-related variability, however, is identified for ETCs near St. John's.

These results provide additional insights into North American ETCs, especially those passing through Eastern Canada. However, there are several issues and limitations, which need to be addressed in future studies. First, our results might be somewhat sensitive to the choice of data set (Froude, 2010), tracking variable (e.g. MSLP instead of relative vorticity; Hoskins and Hodges, 2002) and tracking algorithm (Neu et al., 2013). Although the qualitative results will likely remain unchanged, they could affect quantitative details and statistical significance. Secondly, the cyclone development regions defined in this study cannot be directly compared with specific cyclones that are widely used in synoptic meteorology (e.g. Nor'Easters and Alberta Clippers), as these are defined by more restrictive criteria. This has to be considered when comparing the present study with previous studies. Lastly, the current study does not explicitly relate ETC activity with surface weather. The relationship between the regional ETC tracks and surface weather properties (e.g. temperature, precipitation and wind speed) needs to be better determined.

\section{Acknowledgements}

The authors thank K.I. Hodges for providing us with his tracking algorithm. This project is supported by Fonds de Recherche en Science du Climat d'Ouranos (FRSCO) from the Ouranos Consortium on Regional Climatology and Adaptation to Climate Change, Montreal, Canada. S.W. Son's work is also supported by Basic Science Research Program through the National Research Foundation of Korea (NRF) funded by the Ministry of Education (2013R1A1A1006530).

\section{Appendix}

One recurring issue in cyclone tracking studies is the poor representation of synoptic scale features over high terrain, especially when using pressure levels that intersect the surface (Lareau and Horel, 2012). Grise et al. (2013) showed that tracking ETCs on hybrid sigma-pressure level helps to circumvent this effect over the Rockies. Figure A1 features the winter frequency, intensity, growth and decay rates of ETC tracks computed on the 850-hPa pressure level, to be compared with the hybrid sigma-pressure coordinate results shown in Figures 1 and 2.

A direct comparison of ETC statistics between hybrid sigma-pressure and pressure coordinates reveals a discernible sensitivity only around the Rockies. Specifically, the 850-hPa ETC statistics exhibit a smaller number of ETCs with a weaker intensity over the Rockies (see also 

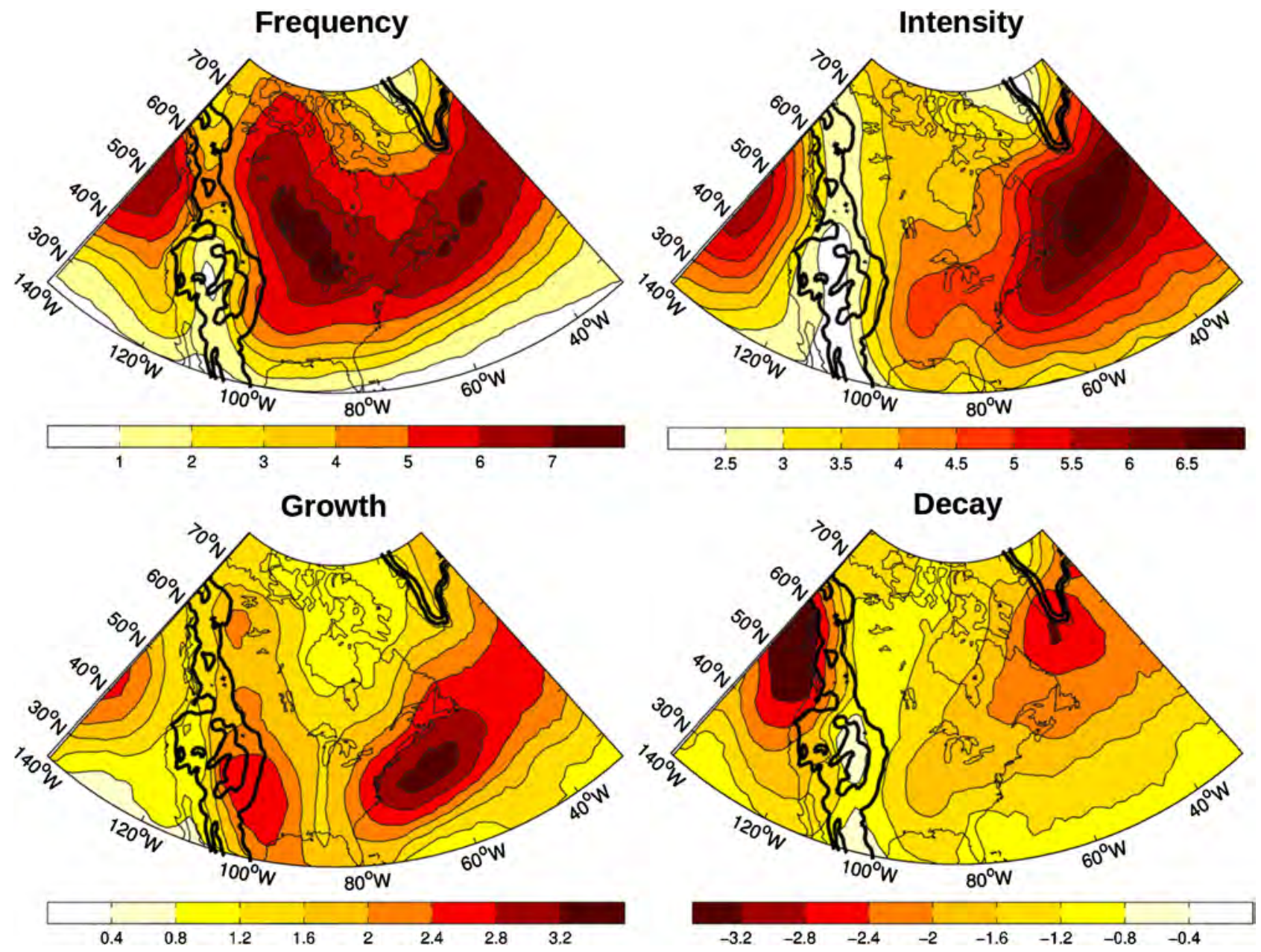

Figure A1. Same as top rows of Figures 1 and 2, but with ETC tracks computed on ERA-Interim 850 hPa pressure level: Climatological winter ETC frequency, intensity, growth and decay.

Grise et al., 2013). Because ETC intensity is almost identical in other regions, this results in stronger growth rates on the lee side of the Rockies and faster decay rates along the western coast of North America in isobaric ETC statistics. However, the physical meaning of this sensitivity is unclear as the $850-\mathrm{hPa}$ isobaric surface intersects the ground in these regions. Note here that because ETC statistics at a given grid point account for all ETCs within a $555-\mathrm{km}$ radius (see Section 2.3), the artefacts of ground intersection are experienced over a broad region in our ETC statistics.

The above sensitivity can affect the characteristics of local ETC activity. An example is illustrated in Figure A2 (top panel bars) for Toronto. The ETCs originating from the Central Rockies become more frequent but those from the Great Lakes become less frequent when isobaric ETC statistics are used instead of hybrid sigma-pressure level statistics. More quantitatively, about 20\% of Toronto's ETCs that develop over the Great Lakes and Hudson Bay are redistributed as cyclones from the Central and Northern Rockies in Figure A2. This result is consistent with an enhanced growth rate on the lee side of the Rockies in isobaric coordinates (Figure A1).
However, it is important to note that qualitative results do not change much even if the uncertainty associated with the choice of vertical coordinate is taken into account. For instance, the two dominant regions of Toronto ETC development are the Central Rockies and Great Lakes. Their variabilities during ENSO years are also very similar in the two vertical coordinates (coloured bars of Figure A2). Providing that isobaric ETC statistics around the Rockies may not be physically meaningful, these similarities suggest that a hybrid sigma-pressure level is a useful alternative for North American cyclone studies.

Figure A2 also presents the sensitivity of Toronto ETCs to the intensity threshold and the radius of influence used to calculate the ETC statistics. It is shown that changing the intensity threshold of ETC from 1 to $3 \mathrm{CVU}$ has virtually no impact on the results (middle row). Similarly, although changing the radius of influence from 333 to $777 \mathrm{~km}$ increases the number of cyclones detected, the relative number of cyclones originating from each development region remains unchanged until the radius is large enough to reach the East Coast and is contaminated by East Coast cyclones. 
(a) 3 Sensitivity : sigma-pressure vs. Pressure level

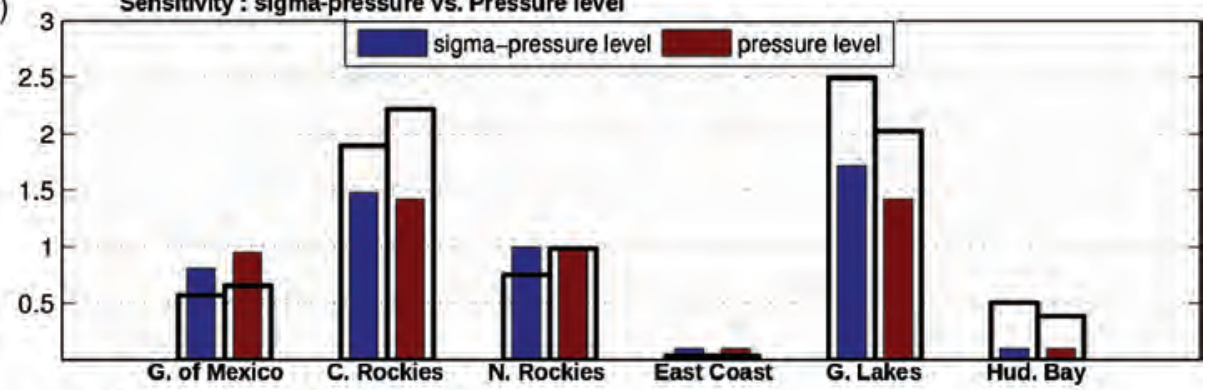

(b) 3 Sensitivity : intensity threshold

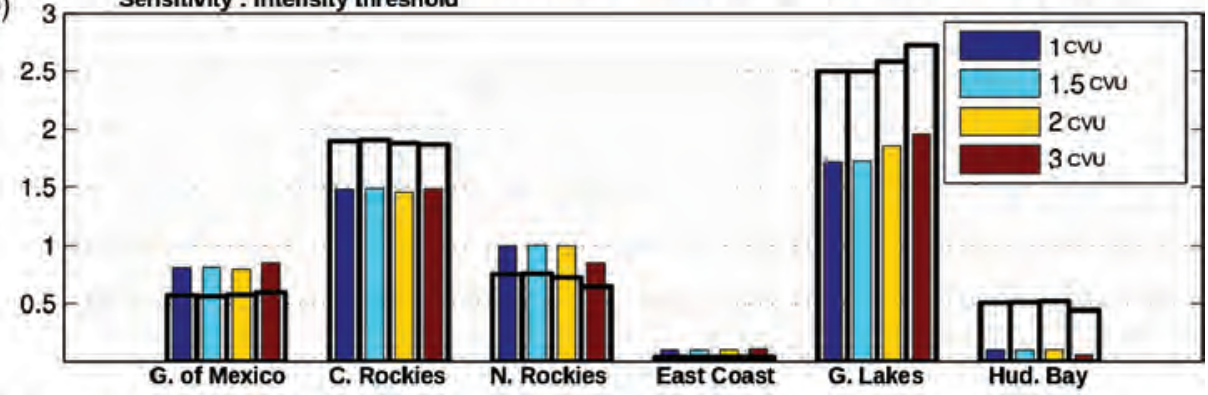

(C) 3 Sensitivity : radius of influence

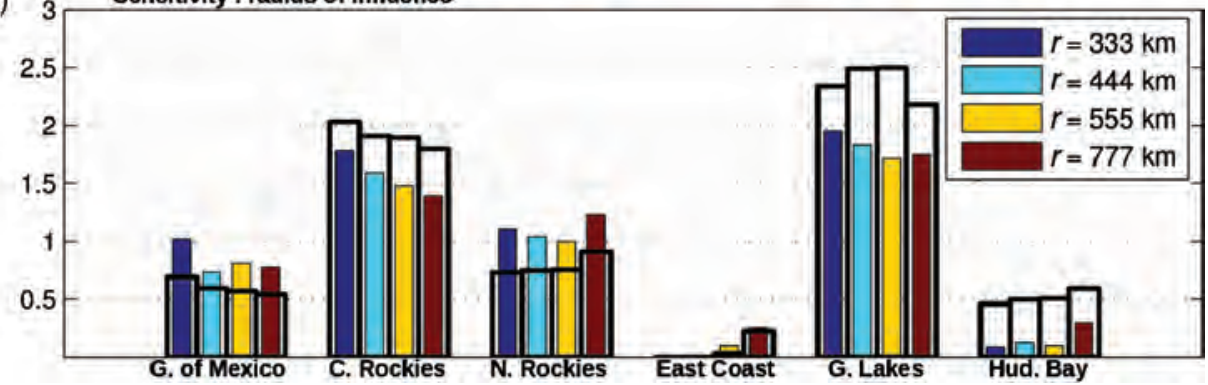

Figure A2. Sensitivity of the distributions of the origin of ETCs near Toronto to: (a) the use of 850-hPa pressure level instead of 857-hPa hybrid sigma-pressure level, (b) the minimum intensity required for cyclone detection, (c) the radius of influence associated with the city. The empty bars denote the climatology, and the coloured bars denote the +ENSO anomaly.

\section{References}

Albright MD, Reed RJ. 1995. Origin and structure of a numerically simulated polar low over Hudson Bay. Tellus A 47: 834-848.

Archambault HM, Bosart LF, Keyser D, Aiyyer AR. 2008. Influence of large-scale flow regimes on cool-season precipitation in the northeastern United States. Mon. Weather Rev. 136: 2945-2963, doi: 10.1175/2007MWR2308.1.

Bengtsson L, Hodges KI, Keenlyside N. 2009. Will extratropical storms intensify in a warmer climate? J. Clim. 22: 2276-2301, doi: 10.1175/2008JCLI2678.1.

Birk K, Lupo AR, Guinan P. 2010. The interannual variability of midwestern temperatures and precipitation as related to the ENSO and PDO. Atmosfera 23: 95-128.

Bradbury JA, Keim BD, Wake CP. 2003. The influence of regional storm tracking and teleconnection of winter precipitation of the Northeastern United States. Ann. Assoc. Am. Geogr. 93: 37-41.

Chang EKM, Guo Y, Xia X. 2012. CMIP5 multimodel ensemble projection of storm track change under global warming. J. Geophys. Res. 117: D23118, doi: 10.1029/2012JD018578.

Changnon D, Noel J, Maze L. 1995. Determining cyclone frequencies using equal-area circles. Mon. Weather Rev. 123: 2285-2294.

Colucci SJ. 1976. Winter cyclone frequencies over the eastern United States and adjacent western Atlantic 1964-1973. Bull. Am. Meteorol. Soc. 57: 548-553.

Dee DP, Uppala SM, Simmons AJ, Berrisford P, Poli P, Kobayashi S, Andrae U, Balmaseda MA, Balsamo G, Bauer P, Bechtold P, Beljaars ACM, van de Berg L, Bidlot J, Bormann N, Delsol C, Dragani R, Fuentes M, Geer AJ, Haimberger L, Healy SB, Hersbach H, Hólm EV, Isaksen L, Kållberg P, Köhler M, Matricardi M, McNally AP, Monge-Sanz BM, Morcrette J-J, Park B-K, Peubey C, de Rosnay P, Tavolato C, Thépaut J-N, Vitart F. 2011. The ERA-Interim reanalysis: configuration and performance of the data assimilation system. $Q . J$. R. Meteorol. Soc. 137: 553-597, doi: 10.1002/qj.828.

Eichler T, Higgins W. 2006. Climatology and ENSO-related variability of North American extratropical cyclone activity. J. Clim. 19: 2076-2093.

Frankoski NJ, DeGaetano AT. 2011. An East Coast winter storm precipitation climatology. Int. J. Climatol. 31: 802-814, doi: 10.1002/joc. 2121 .

Froude LSR. 2010. TIGGE: comparison of the prediction of Northern Hemisphere extratropical cyclones by different ensemble prediction systems. Weather Forecast. 25: 819-836, doi: 10.1175/2010WAF2222326.1

Grise KM, Son S-W, Gyakum JR. 2013. Intraseasonal and interannual variability in North American storm tracks and its relationship to equatorial Pacific variability. Mon. Weather Rev. 141: 3610-3625.

Gyakum JR, Anderson JR, Grumm RH, Gruner EL. 1989. North Pacific cold-season surface cyclone activity: 1975-1983. Mon. Weather Rev. 117: $1141-1155$.

Hawcroft MK, Shaffrey LC, Hodges KI, Dacre HF. 2012. How much Northern Hemisphere precipitation is associated with extratropical cyclones? Geophys. Res. Lett. 39: L24809, doi: 10.1029/2012GL053866.

Hirsch ME, DeGaetano AT, Colucci SJ. 2001. An East Coast winter storm climatology. J. Clim. 14: 882-899.

Hodges KI. 1994. A general-method for tracking analysis and its application to meteorological data. Mon. Weather Rev. 122: $2573-2586$.

Hodges KI. 1995. Feature tracking on the unit sphere. Mon. Weather Rev. 123: $3458-3465$.

Hodges KI. 1999. Adaptive constraints for feature tracking. Mon. Weather Rev. 127: 1362-1373. 
Hoskins BJ, Hodges KI. 2002. New perspectives on the Northern Hemisphere winter storm tracks. J. Atmos. Sci. 59: 1041-1061.

Isard SA, Angel JR, VanDyke GT. 2000. Zones of origin for Great Lakes cyclones in North America, 1899-1996. Mon. Weather Rev. 128: $474-485$.

Klein WH. 1951. The weather and circulation of November 1951. Mon. Weather Rev. 79: 208-211, doi: 10.1175/1520-0493(1951)079<0208: TWACON $>2.0 . \mathrm{CO} ; 2$.

Klein WH. 1957. The frequency of cyclones and anticyclones in relation to the mean circulation. J. Meteorol. 15: 98-102.

Lareau NP, Horel JD. 2012. The climatology of synoptic-scale ascent over western North America: a perspective on storm tracks. Mon Weather Rev. 140: 1761-1778, doi: 10.1175/MWR-D-11-00203.1.

Mesquita MDS, Gunnar Kvamstø N, Sorteberg A, Atkinson DE. 2008. Climatological properties of summertime extra-tropical storm tracks in the Northern Hemisphere. Tellus A 60: 557-569, doi: 10.1111/j.1600-0870.2008.00305.x.

Murray RJ, Simmonds I. 1991. A numerical scheme for tracking cyclone centers from digital data. Part I: development and operation of the scheme. Aust. Meteorol. Mag. 39: 155-166.

Neu U, Akperov MG, Bellenbaum N, Benestad R, Blender R, Caballero R, Cocozza A, Dacre HF, Feng Y, Fraedrich K, Grieger J, Gulev S, Hanley J, Hewson T, Inatsu M, Keay K, Kew SF, Kindem I, Leckebusch GC, Liberato MLR, Lionello P, Mokhov II, Pinto JG, Raible CC, Reale M, Rudeva I, Schuster M, Simmonds I, Sinclair M, Sprenger M, Tilinina ND, Trigo IF, Ulbrich S, Ulbrich U, Wang XL, Wernli H. 2013. IMILAST: a community effort to intercompare extratropical cyclone detection and tracking algorithms. Bull. Am. Meteorol. Soc. 94: 529-547, doi: 10.1175/BAMS-D-11-00154.1.
Noel J, Changnon D. 1998. A pilot study examining U.S. winter cyclone frequency patterns associated with three ENSO parameters. J. Clim. 11: $2152-2159$

Notaro M, Wang W-C, Gong W. 2006. Model and observational analysis of the northeast U.S. regional climate and its relationship to the PNA and NAO patterns during early winter. Mon. Weather Rev. 134: 3479-3505.

Reitan CH. 1974. Frequencies of cyclones and cyclogenesis for North America, 1951-1970. Mon. Weather Rev. 102: 861-868.

Serreze MC. 1995. Climatological aspects of cyclone development and decay in the Arctic. Atmos. Ocean 33: 1-23.

Shabbar A, Barnston AG. 1996. Skill of seasonal climate forecasts in Canada using canonical correlation analysis. Mon. Weather Rev. 124: $2370-2385$

Sinclair MR. 1994. An objective cyclone climatology for the Southern Hemisphere. Mon. Weather Rev. 122: 2239-2256.

Smith TM, Reynolds RW, Peterson TC, Lawrimore J. 2008 Improvements to NOAA's historical merged land-ocean surface temperature analysis (1880-2006). J. Clim. 21: 2283-2296, doi: 10.1175/2007JCLI2100.1.

Wang XL, Wan H, Swail VR. 2006. Observed changes in cyclone activity in Canada and their relationships to major circulation regimes. J. Clim. 19: 896-915.

Zappa G, Shaffrey LC, Hodges KI. 2013. The ability of CMIP5 models to simulate North Atlantic extratropical cyclones. J. Clim. 26: 5379-5396, doi: 10.1175/JCLI-D-12-00501.1.

Zishka K, Smith P. 1980. The climatology of cyclones and anticyclones over North America and surrounding ocean environs for January and July, 1950-1977. Mon. Weather Rev. 108: 387-401. 